Case Report:

\title{
Symptomatic Unilateral Subdural Effusion as the First crossmark Presentation of Suprasellar Arachnoid Cyst
}

Omidvar Rezaei ${ }^{1}$, Karim Moradian-Kokhdan ${ }^{2 *}$, Kaveh Ebrahimzadeh ${ }^{3}$, Saeed Razmeh ${ }^{1}$, Guive Sharifi ${ }^{1}$, Mohammad Samadian ${ }^{1}$

1. Department of Neurosurgery, Loghman Hakim Hospital, Shahid Beheshti University of Medical Sciences, Tehran, Iran

2. Department of Neurosurgery, Faculty of Medicine, Kermanshah University of Medical Sciences, Kermanshah, Iran

3. Department of Neurology, Faculty of Medicine, Yasuj University of Medical Sciences, Kohgiluyeh and Boyer-Ahmad, Iran

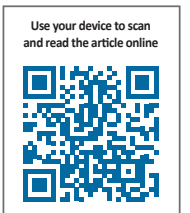

Citation: Rezaei O, Moradian-Kokhdan K, Ebrahimzadeh K, Razmeh S, Sharifi G, Samadian M. Symptomatic Unilateral Subdural Effusion as the First Presentation of Suprasellar Arachnoid Cyst. Iran J Neurosurg. 2017; 3(3):115-118. https://doi.org/10.29252/ IRJNS.3.3.115

https://doi.org/10.29252/IRJNS.3.3.115

Article info:

Received: 03 June 2017

Last Revised: 19 August 2017

Accepted: 27 August 2017

Keywords:

Subdural effusion, Suprasellar, Arachnoid cyst

\section{ABSTRACT}

Background and Importance: Arachnoid cysts are benign nontumoral lesions that are usually found incidentally in brain imaging. Suprasellar Arachnoid Cysts (SSACs) are rare. They can cause hydrocephalus and increased intracranial pressure, lower cranial nerve impairment and endocrine disorder. Sometimes arachnoid cysts become complicated by subdural hematoma/ hygroma.

Case Presentation: We describe a patient with a suprasellar arachnoid cyst that was complicated with symptomatic subdural effusion and increased intracranial pressure after minor trauma.

Conclusion: Although these cysts are rarely complicated with subdural hematoma/hygroma, and intracystic hemorrhage, the probability of subsequent subdural hygroma and increased intracranial pressure should not be underestimated.

\section{Background and Importance}

rachnoid cysts are rare intra-arachnoid collections of Cerebrospinal Fluid (CSF) that are usually congenital [1]. Many of these mass lesions are asymptomatic but can present with increased Intracranial Pressure (ICP), intracystic hemorrhage and subdural hematoma/hygroma [2]. Most of them are located in the supratentorial region in middle cranial fossa and less frequently in cerebral convexities, cerebellopontine angle, cisterna magna, suprasellar and quadrigeminal cisterns. Suprasellar Arachnoid Cysts (SSACS) are rare. They constitute 10\% of all arachnoid cysts and can occlude the aqueduct and third ventricle and result in hydrocephalus [3, 4]. A rare presentation of arachnoid cysts is subdural hygroma. In this study, we present a patient with a suprasellar arachnoid cyst that became complicated with subdural hygroma.

* Corresponding Author: 

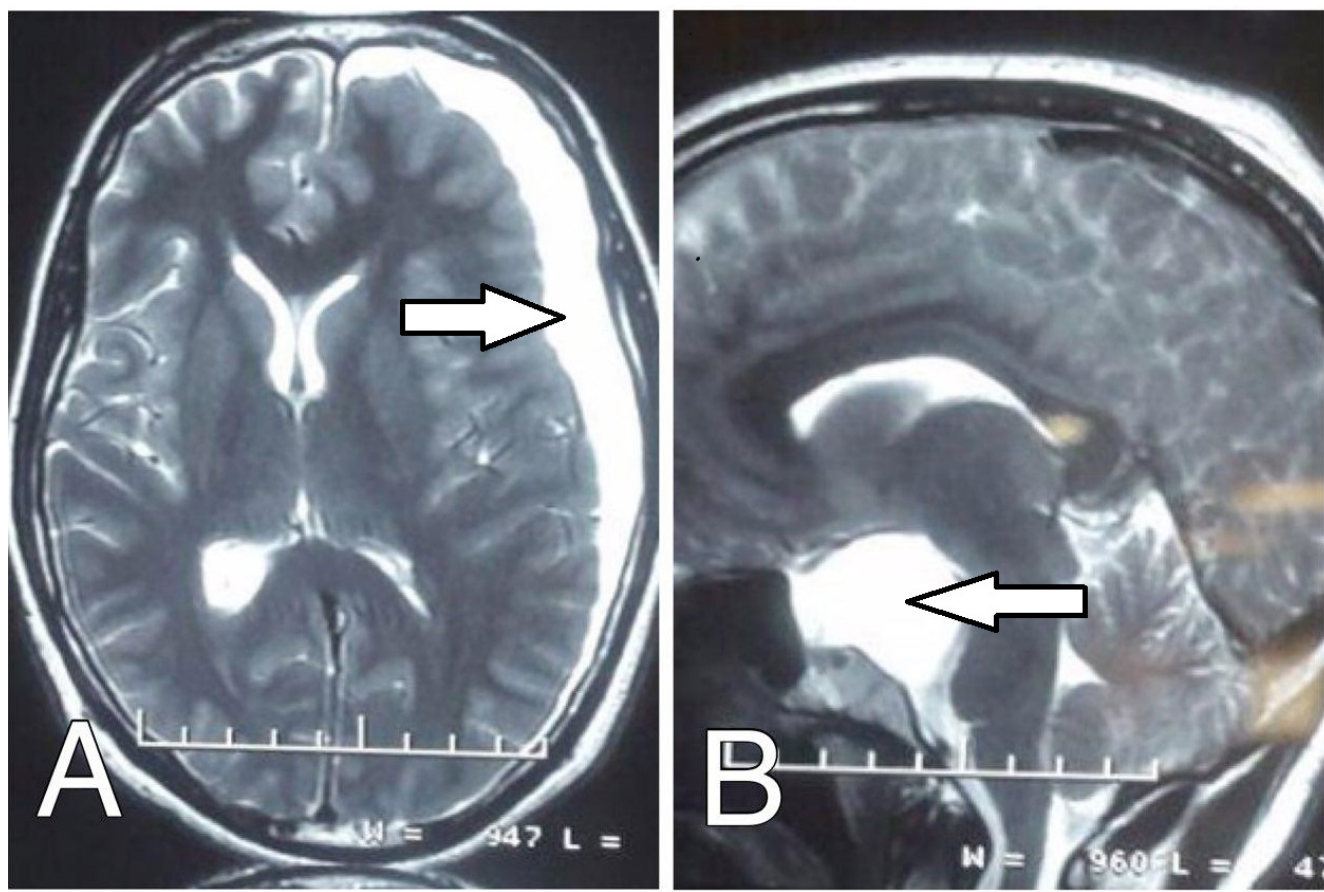

\section{NS}

Figure 1. A: Axial T2 weighted MRI showing the left subdural effusion with compression effect, B: Sagittal MRI showing suprasella arachnoid cyst

\section{Case Presentation}

A 25-year-old man was referred to Loghman $\mathrm{Ha}$ kim Hospital, Tehran, with a chief complaint of headache, nausea, vomiting and right hemiparesis. The early symptoms had begun 1 month earlier after minor trauma in which the patient had undergone burr hole twice due to recurrent left subdural effusion then he was discharged. The signs and symptoms recurred again after discharge which made him refer to our center. Previous medical and family history was unremarkable. In physical examination, he had an orientation to time, place and person. The neurological examination revealed right hemiparesis. The brain Magnetic Resonance Imaging (MRI) showed the suprasellar cyst lesion causing stretching and anterior compression of the midbrain, pons, and optic chiasm with superior extension to the third ventricle with an associated left subdural hematoma, with the compression effect on the ventricles (Figure 1). The patient underwent left craniotomy with pterional approach, subdural effusion was evacuated then the arachnoid cyst was fenestrated to adjacent cisterna basalis. All of the signs and symptoms improved after surgery and in follow-up visits after discharge.

\section{Discussion and Conclusion}

Arachnoid cysts are usually asymptomatic, and many of these cysts are detected incidentally in the brain CT and MRI. The typical presentations are obstructive hydrocephalus, increased intracranial pressure and visual changes, endocrine abnormalities and head bobbing $[5,6]$. These cysts are rarely complicated with subdural hematoma/hygroma, and intracystic hemorrhage [7]. SSACs are rare and they comprise $2 \%$ of all cysts, usually reported in the pediatric population $[8,9]$. They can cause hydrocephalus and lower cranial nerve impairment and endocrine disorder including amenorrhea, precocious puberty, developmental delay and growth retardation [6]. Fahad et al. reported a case that presented with precocious true puberty. The neurological deficit also can arise from the compression of adjacent structures $[10,11]$. The exact pathogenesis of subdural hematoma has not been detected so far. Moreover, trauma may have a role in the formation of subdural hygroma and increased intracranial pressure as well as in compression of adjacent structure [12]. There are various treatments for the SSAC including craniotomy and open fenestration and endoscopic technique for establishing normal CSF flow by communication between the arachnoid cyst and intraventricular or subarachnoid space [13]. Our patient had supracerebellar cyst that 
complicated with subdural hygroma and increased intracranial pressure. He was treated surgically.

\section{Acknowledgments}

This research did not receive any specific grant from funding agencies in the public, commercial, or not-forprofit sectors.

\section{Conflict of Interest}

The authors declare that they have no conflicts of interest. Authors' contribution is as follows: Conception and Design: All authors; Data Collection: Karim Moradian-Kokhda; Drafting the Article: All authors; Critically Revising the Article: All authors; Reviewing Submitted Version of Manuscript: All authors; and Approving the Final Version of the Manuscript: All Authors.

\section{References}

[1] Al-Holou WN, Terman S, Kilburg C, Garton HJ, Muraszko KM, Maher CO. Prevalence and natural history of arachnoid cysts in adults. Journal of Neurosurgery. 2013; 118(2):222-31. doi: 10.3171/2012.10.JNS12548

[2] Helland CA, Wester K. A population based study of intracranial arachnoid cysts: clinical and neuroimaging outcomes following surgical cyst decompression in adults. Journal of Neurology, Neurosurgery \& Psychiatry. 2007; 78(10):1129-35. doi: 10.1136/jnnp.2006.107995

[3] Westermaier T, Schweitzer T, Ernestus RI. Arachnoid cysts. in: Ahmad SI, editor. Neurodegenerative Diseases. Berlin: Springer; 2012.

[4] Campistol JP, Costa JC, Fernandez-Alvarez E. [Intracranial arachnoid cysts in children. Review of 34 cases (Spanish)]. Anales espanoles de pediatria. 1983; 19(6):459-70. PMID: 6666888

[5] Wiese JA, Gentry LR, Menezes AH. Bobble-head doll syndrome: Review of the pathophysiology and CSF dynamics. Pediatric Neurology. 1985; 1(6):361-6. doi: 10.1016/08878994(85)90073-6

[6] Adan L, Bussières L, Dinand V, Zerah M, Pierre-Kahn A, Brauner R. Growth, puberty and hypothalamic-pituitary function in children with suprasellar arachnoid cyst. European Journal of Pediatrics. 2000; 159(5):348-55. doi: 10.1007/ s004310051285

[7] Rajendra S, Reeka P, Xu J, You C. Arachnoid cyst complicated by spontaneous Chronic Subdural Hematoma in the infant. Romanian Neurosurgery. 2012; 19:1.

[8] Harsh IV GR, Edwards MS, Wilson CB. Intracranial arachnoid cysts in children. Journal of Neurosurgery. 1986; 64(6):835-42. doi: 10.3171/jns.1986.64.6.0835
[9] André A, Zérah M, Roujeau T, Brunelle F, Blauwblomme $\mathrm{T}$, Puget $\mathrm{S}$, et al. Suprasellar arachnoid cysts: Toward a new simple classification based on prognosis and treatment modality. Neurosurgery. 2016; 78(3):370-80. doi: 10.1227/ neu.0000000000001049

[10] Al Badr FB, Al Sultan SA. Precocious true puberty secondary to a suprasellar arachnoid cyst: A case report and MR characteristics of common suprasellar cystic lesions. The Egyptian Journal of Radiology and Nuclear Medicine. 2012; 43(2):245-8. doi: 10.1016/j.ejrnm.2012.02.007

[11] Raju S, Sharma RS, Moningi S, Momin J. Neuroendoscopy for intracranial arachnoid cysts in infants: Therapeutic considerations. Journal of Neurological Surgery Part A: Central European Neurosurgery. 2016; 77(04):333-43. doi: 10.1055/s0034-1396434

[12] Gui SB, Wang XS, Zong XY, Zhang YZ, Li CZ. Suprasellar cysts: Clinical presentation, surgical indications, and optimal surgical treatment. BMC Neurology. 2011; 11(1):52. doi: $10.1186 / 1471-2377-11-52$

[13] Shim KW, Lee YH, Park EK, Park YS, Choi JU, Kim DS, Treatment option for arachnoid cysts. Child's Nervous System. 2009; 25(11):1459-66. doi: 10.1007/s00381-009-0930-7 
